\section{The carbohydrate competition}

\section{Neil Baggett}

Journal of Carbohydrate Chemistry.

Editor Donald E. Kiely.

Dekker. 4/yr.

$\$ 110$ (US), \$121 (elsewhere). Chemistry (JCC), which in part replaces the Journal of Carbohydrates, Nucleosides, Nucleotides, is to provide an international forum for aspects of carbohydrate chemistry, excluding polysaccharide studies. This area of chemistry is already served by Carbohydrate Research, so that JCC does not fill a vacant niche but competes with the established journal. It is therefore appropriate to compare the two.

The new journal includes original research papers and communications, with some reviews of "timely topics in carbohydrate chemistry". Carbohydrate Research does not contain reviews but does cover studies on polysaccharides. Both journals publish articles in English (mainly), but also in French and German. The new journal comprises four issues per year (six were originally promised), so it is much smaller but also much cheaper than its competitor; the two are roughly comparable in terms of price per page. Perhaps the most noticeable difference between the journals is that JCC is repro-
THE aim of the Journal of Carbohydrate

duced direct from the authors' typescripts, which means that very rapid publication can be achieved but also, on occasions, that minor but necessary editing is not done. Together with the non-uniformity of type, this gives the journal a rather unfinished look, and the principal attraction of JCC for potential authors must be the speed of publication.

The claim to be an international journal is justified. There are representatives from 13 countries on the editorial board and the papers published to date originate from a wide geographical range. There is, however, a bias towards the United States, with almost half of the editorial board and one-third of papers coming from that country.

So far the standard of papers and reviews in the new journal is generally good, perhaps because roughly half of them have been contributed by members of the editorial board. The viability of JCC will depend on whether papers of a similar quality are forthcoming in the future from a broader range of authors, especially if the American Chemical Society continues to expand its range of publications into the area of carbohydrate chemistry. Whilst there are advantages for authors in having two journals to choose between, librarians are not in such a happy position - the standard of the papers in both JCC and Carbohydrate Research means that neither can be just ignored.

Neil Baggett is a Lecturer in the Department of Chemistry, University of Birmingham, UK.

Submissions are refereed, and must contain experimental details (a refreshing feature to be recommended to the editors of other journals devoted to the rapid publication of scientific research). Authors of review articles are encouraged to include critical comments, and thus far reviewers are responding and are doing more than simply providing compilations of the literature pertaining to a given subject. Lately, abstracts of recent articles and biblio-

Nucleosides and Nucleotides (NN) is unashamedly a speciality journal, but one which covers an especially vigorous area of science. Its aim is to concentrate upon the chemistry and biology of nucleosides, nucleotides and closely related compounds, with the chemistry of new entities being emphasized.

Obviously, for this, as for most new journals, success in the long run will depend upon the submission of material from authors who generally send their papers to more established publications. Judging by the eminence of some of the contributors to the first two volumes, NN has made an auspicious beginning. And although the journal is reproduced from camera-ready copy, the standard of production is very high - reviews, original articles and notes are clearly presented, with chemical structures, tables and so on embedded as appropriate in the text.

\section{Nucleosides \& Nucleotides}

graphical data on selected subjects have been added to the journal's contents.

Anyone working in this field, or wishing to enter it, will need to refer to NN for information on developments in the chemistry and biology of nucleic acids, for indications of new directions the field is taking, as well as for the comprehensive reviews which appear from time to time. The subscription price is not unreasonable, and altogether the journal seems set for a healthy future.

Janet L. Rideout is a Group Leader in the Organic Chemistry Department at Burroughs Wellcome, Research Triangle Park, North Carolina.

\section{With the grain}

\section{Donald D. Kasarda}

Journal of Cereal Science.

Editor T. Galliard.

Academic. 4/yr. £43, \$98.

BECAUSE of the enormous importance of cereal grains as food, animal feeds and raw materials, almost every cereal-producing country in the world - from Australia to the USSR - has in recent years made huge investments in cereals research. Such expansion has created a need for extra journals as outlets for the resulting publications. The new Journal of Cereal Science (JCS) covers much the same areas as the already well-established journal Cereal Chemistry, including research papers (and an occasional review) on topics such as component characterization, nutritional quality, food science and technology, and genetics as they relate to the functional or nutritional quality of cereal grains (unlike Cereal Chemistry, however, JCS does not accept papers on legume "grains").

I have the impression that, in addition to a need for more journal space, the impetus for the formation of JCS stemmed partly from dissatisfaction by some scientists (particularly in Britain and France) with what they considered unfortunate reviewing practices by Cereal Chemistry that delayed publication of papers. They were also unhappy with the page charges levied by that journal. Since then, it should be said, Cereal Chemistry has dealt with many of its problems although the page charges remain.

My examination of five of the six issues out at the time of writing tells me that JCS is doing well; many papers are of a high standard, the quality of editing and of production are good, publication occurs a not-unreasonable six to ten months after receipt of a manuscript, and there are no page charges.

A few papers seem rather pedestrian, however, and such contributions may discourage authors from choosing this journal to publish their better work. On the other hand, authors must contend with the tendency of editors of the better generalscience journals to recommend that papers dealing with cereal grains, even reasonably good ones, should be published in speciality journals. Such attitudes, however unfortunate, benefit Cereal Chemistry and now, I suspect, JCS as well.

I believe this new journal is here to stay. Not only that, the commitment to improved quality evident in occasional editorials by the editor T. Galliard, and one of his colleagues, J. D. Schofield, should lead to expansion.

Donald D. Kasarda is Research Leader of the Food Proteins Research Unit, Western Regional Research Center, ARS, US Department of Agriculture, Albany, California. 